The Egyptian Journal of Hospital Medicine (Oct. 2012) Vol., 49: 732- 750

\title{
ROLE OF MULTISLICE COMPUTED TOMOGRAPHY IN PATIENTS PRESENTING WITH HEMOPTYSIS
}

\author{
Amr M Ismaeel, Mohamed A Nassef, Maha F Azmy and Magdy M Khalil
}

Radiodiagnosis department, Faculty of Medicine, Ain Shams University

\begin{abstract}
We described the role of MDCT with its new applications for determining the cause and site of bleeding, and to determine the additional benefit of MDCT angiographic technique in identifying the site of bleeding and its vascular origin.
\end{abstract}

PATIENTS AND METHODS: 50 patients suffering from hemoptysis were evaluated by MDCT with its new applications \& MDCT angiographic technique.

RESULTS: MDCT revealed excellent diagnostic method for hemoptysis.

CONCLUSION: MDCT is considered a primary noninvasive imaging modality in the evaluation of patients with hemoptysis. It also serves as a guide for other diagnostic or therapeutic procedures.

Keywords: MDCT and Hemoptysis - MDCT angiographic

\section{INTRODUCTION}

Hemoptysis is defined as bleeding originates from the lower respiratory tract. ${ }^{(1)}$ Although hemoptysis may cease temporarily, a possible life-threatening condition may still be present, requiring complete evaluation and treatment. (2) Hemoptysis' severity is classically classified based on the amount of bleeding. ${ }^{(3)}$ There are multiple causes of hemoptysis, from airway diseases, parenchymal diseases, cardiovascular diseases, and other causes. (2) The common causes of bleeding from the large vessels nowadays include cancer, bronchiectasis, tuberculosis, and fungal infections. No cause is identified in $15 \%$ to $30 \%$ of all cases, and is termed idiopathic or cryptogenic hemoptysis. ${ }^{(4)}$ The most common underlying causes of hemoptysis vary in reported studies depending on the geographic location of the study, the prevalence of tuberculosis, and the use of crosssectional imaging. ${ }^{(5)}{ }^{(6)}$ The bronchial arteries are the source of bleeding in most cases of hemoptysis; while hemoptysis is related to pulmonary artery injury in up to $11 \%$ of cases. ${ }^{(8)}$ Contributions from the non-bronchial systemic arterial system represent an important cause of recurrent hemoptysis following apparently successful bronchial artery embolization. Vascular anomalies such as pulmonary arteriovenous malformations and bronchial artery aneurysms are other important causes of hemoptysis. (5) Conditions such as bronchiectasis, chronic bronchitis, lung malignancy, tuberculosis, and chronic fungal infection are easily detected with conventional CT. ${ }^{(5)}$ MDCT permits a more sensitive, more rapid and accurate assessment of the cause and 


\section{ROLE OF MULTISLICE COMPUTED TOMOGRAPHY....}

consequences of hemorrhage into the airways and helps guide subsequent management. ${ }^{(5)} \mathrm{CT}$ is superior to fiberoptic bronchoscopy in finding a cause of hemoptysis, its main advantage being its ability to show distal airways beyond the reach of the bronchoscope, and the lung parenchyma surrounding these distal airways. ${ }^{(4)}$ Data suggest that CT could replace bronchoscopy as the first-line procedure for screening patients with severe hemoptysis. (7) The addition of MDCT angiography provides a more precise depiction of the bronchial arteries than conventional angiography. ${ }^{(8)}$ The aim of the current study is to describe the role of MDCT with its new applications such as reformatted images, high resolution imaging, and post-processing techniques, for determining the cause and site of bleeding, and to determine the additional benefit of MDCT angiographic technique in identifying the site of bleeding and its vascular origin.

\section{PATIENTS AND METHODS}

This study was carried out on 50 patients suffering from hemoptysis and referred from chest department in Demerdash hospital to nongovernmental centers. This study was approved by our medical human ethics, and written informed consent was obtained from all patients.

Exclusion criteria included:

The following patients were excluded from the current study:

- Pregnant females.

- Patients with chronic renal failure (or impairment) not on regular dialysis.
- Patients who are hemodynamically unstable.

- Severe cardiac disease causing orthopnea.

- Sensitivity to the contrast medium.

- Patients with life-threatening hemoptysis till been stabilized.

All patients were subjected to complete clinical assessment. The volume of hemoptysis corresponds to the cumulated amount of bleeding, which was assessed from the onset of bleeding until time of CT examination using a standardized scale: spoonful ( $5 \mathrm{~mL})$, small filled glass $(100 \mathrm{~mL})$, and large filled glass $(200 \mathrm{~mL})$. According to the severity of hemoptysis, it was classified as "mild" (<30 cm3), "moderate" (30$600 \mathrm{~cm} 3)$, "severe" or "massive" (>600 cm3). Full clinical examination was carried out. Also laboratory data were reviewed. Chest $\mathrm{X}$ ray were performed for all patient prior to CT study and was reviewed for any abnormality.

Patient preparation: All patients were instructed to fast 4-6 hours prior to the examination. All steps of the study were explained in details for each patient. All image acquisition was performed in inspiratory breath-hold. An IV access was secured (an $18 \mathrm{G}$ cannula). The access sites were the antecubetal vein.

Scan protocol: MDCT study obtained using either Toshiba Aquilion 64 CT scanner (Toshiba, aquilion 64 slice, Japan) or general electric (Light Speed Ultra 16; GE Medical Systems). The IV line was then connected to the dual head injector.

The routine MDCT chest procedure Coverage was from the base of the neck to the level of the 
renal arteries. $50 \mathrm{ml}$ of nonionic, low osmolar contrast agent was injected. The automatic bolus-triggering software program was systematically applied, with a circular region of interest positioned at the descending aorta, and as the threshold value of $100 \mathrm{HU}$ was approached, craniocaudal scanning started. This was followed by saline-flushing by injection of about $50 \mathrm{cc}$ saline solution.

The MDCT bronchial angiographic technique: CT imaging had acquired from the supraclavicular area to the level of the ostia of the renal arteries, including the supraaortic great vessels and the infra-diaphragmatic arteries, which may also supply collateral branches to the lungs. With current multidetector row systems, optimal enhancement of both the pulmonary and systemic arteries were achieved with the injection of $120 \mathrm{~mL}$ of a high-density, low osmolar non-ionic contrast medium $(350 \mathrm{mg} / \mathrm{dL})$ with an automated injector at a rate of $4 \mathrm{~mL} / \mathrm{s}$ via an antecubital vein. The automatic bolustriggering software program was also systematically applied, with a circular region of interest positioned at the descending aorta at the level of carina, and as the threshold value of 100 HU (for 16-detector MDCT) or $120 \mathrm{HU}$ (for 64 detectors MDCT) was approached, craniocaudal scanning started. Thoracic CT angiography with a combination of selected reformatted images is done. Assessment of the lung parenchyma and airways as well as the mediastinum was always done as in routine CT chest studies, using both lung parenchyma and mediastinal window settings.

Post processing techniques: Post-processing of the raw data was performed with axial thinsection images, multiplanner reformation (MPR), interactive maximum intensity projection (MIP), and volume-rendered (VR) techniques in order to optimally evaluate the origins and courses of the bronchial and nonbronchial systemic arteries (NBSAs). Virtual bronchoscopy (VB) was performed in three patients. A virtual endoscopic software program was used to reconstruct the CT data into VB images. The VB images of each patient were studied together with the regular axial CT images and other imaging planes.

\section{Examination Protocols For CT Bronchial Angiography:}

Table no.1: Parameters for MDCT bronchial angiography:

\begin{tabular}{|l|l|l|}
\hline Parameter & 16-Detector Row CT & 64-Detector Row CT \\
\hline Kilovolt peak & $100-140$ & $100-140$ \\
\hline Effective mAs & $90-140$ & $90-120$ \\
\hline Collimation & $16 X 0.75 \mathrm{~mm}$ & 64 X0.6 mm \\
\hline Pitch & 1.5 & 1.2 \\
\hline $\begin{array}{l}\text { Contrast material (non-ionic } \\
\text { iodinated) }\end{array}$ & & \\
\hline Volume $(\mathrm{mL})$ & 120 & 120 \\
\hline Concentration $(\mathrm{mg} / \mathrm{dL})$ & 350 & 350 \\
\hline Injection rate $(\mathrm{mL} / \mathrm{sec})$ & 4 & 4 \\
\hline
\end{tabular}




\section{Data interpretation for routine CT chest:}

- Assess the lung parenchyma to detect the site of bleeding: either to one lung, lobe or segment. If bilateral findings seen, it was considered not definitive.

- Assess the lung parenchyma for the cause of bleeding. Imaging-specific features for the cause were searched for. Focal areas of ground glass opacities or consolidations were considered non-specific findings, as they may represent intra-alveolar hemorrhage as sequelae of hemoptysis rather than the cause.

- Assessment of the associated findings, especially pleural thickening.

\section{Data interpretation for CT angiography study:}

- Assess the lung parenchyma to detect the site and the cause of bleeding as well as any associated findings as done in group I.

- Assessment of the bronchial arteries: as regard the

- Number of bronchial arteries detected on either side.

- The site of origin from the aorta.

- The level of origin related to vertebral bodies (orthotopic or ectopic) and related to tracheal carina (at the level of tracheal carina or below it)

- The traceability of the bronchial arteries at their mediastinal course to the pulmonary hila.

- The diameter of the bronchial arteries at their origin.
- Assessment of the non-bronchial systemic arteries:

- Number

- Origin

- Course

- Assessment of the pulmonary circulation for any abnormality that may cause hemoptysis (e.g. pulmonary embolism, pulmonary AVM, pulmonary aneurysm).

A bronchial artery with a diameter greater than 2 mm was considered abnormal. Enlarged vascular structures entered the lung parenchyma through the inferior pulmonary ligament or through the adherent pleura and associated with pleural thickening $(>3 \mathrm{~mm})$ and lung parenchyma abnormalities were regarded as nonbronchial systemic arteries responsible for hemoptysis. In cases with hemoptysis of pulmonary artery origin, the signs of MDCT were pseudoaneurysm, aneurysm of pulmonary artery, or presence of pulmonary artery in the inner wall of cavity

\section{Results}

The study included 50 patients complaining of hemoptysis. The studied sample included 38 male, 12 female. The mean age of patients was 50 years, with a maximum of 80 year and minimum of 20 year. The most commonly affected age group was above 50 years ( 25 of the 50 patients) $(50 \%)$

\section{The degree of hemoptysis prior to scanning:}

$15(30 \%)$ patients present with mild hemoptysis. $30(60 \%)$ patients had moderate hemoptysis. 5 (10\%) patient presented with 
massive hemoptysis. Of the 5 cases presenting with massive hemoptysis, the CT showed finding of active tuberculosis in 1 patient, of acute pneumonia (1 patient), of bronchiectasis (1 patient), and of lung cancer ( 2 patients).

The cause of hemoptysis: The cause of hemoptysis was primarily diagnosed from the patient's history, physical examination and chest radiography. Final diagnosis was established applying all clinical, laboratory, radiographic, MDCT, bronchoscopic, conventional angiographic findings and histopathology (if done). Chest $\mathrm{X}$ ray was done in all patients. Many radiographic findings have been identified, including localized patch of consolidation in 4 patients (8\%), mass in 12 patients $(24 \%)$, bronchiectasis in 3 patients $(6 \%)$, and cavitary lesion in 3 patients $(6 \%)$. Plain radiography was considered successfully contributing in identification of the cause of hemoptysis in only $22 / 50$ patients (44\%). Fiberoptic bronchoscopy was done in 7 patients (14\%) with moderate or severe hemoptysis. It revealed the cause of bleeding in 6 patients $(85.7$ $\%), 3$ patients had central bronchogenic carcinoma (proved by histopathological confirmation), 2 patients had focal endobronchial mass and 1 patient had bronchiectasis. Biopsy was taken from the 5 patients with central or endobronchial masses. Hemoptysis complicated a known disease in 6 patients (bronchiectasis in 3 patients, active TB in 1 patient, lung cancer in 2 patients).

\section{The patients were divided into two groups:}

Group I included 30 patients underwent routine MDCT of the chest with application of the new advances in MDCT techniques, such as MPR and MIP. Virtual bronchoscopy was added in three patients.

Table 2 shows the chest CT findings in the group I as regard the cause of bleeding. Applying all clinical, laboratory and CT findings, the cause of hemoptysis was reached in $27(90 \%)$ cases. Finally, the diagnosis of 3 (10 $\%$ ) patients remained unknown and the presumed diagnosis was idiopathic hemoptysis.

Table (2): Shows the chest CT findings of the cause of bleeding in the group I:

\begin{tabular}{|c|c|c|}
\hline CT findings & Number & Percentage \\
\hline \multicolumn{3}{|l|}{ Specific parenchymal abnormality } \\
\hline - Lung mass & 13 & $43.5 \%$ \\
\hline - Tuberculosis and its sequelae & 4 & $13.3 \%$ \\
\hline - Bronchiectasis & 3 & $10 \%$ \\
\hline - $\quad$ Endobronchial mass & 2 & $6.7 \%$ \\
\hline - $\quad$ Fungal (intra-cavitary mycetoma) & 1 & $3.3 \%$ \\
\hline \multicolumn{3}{|l|}{ Non-specific parenchymal abnormality } \\
\hline $\begin{array}{l}\text { - Focal increased lung density } \\
\text { • Diagnosed as pneumonia } \\
\text { - Non-specific intra-alveolar hemorrhage or } \\
\text { aspiration }\end{array}$ & $\begin{array}{ll}\text { - } & 2 \\
\text { - } & 1\end{array}$ & $10 \%$ \\
\hline $\begin{array}{l}\text { No parenchymal abnormality } \\
\text { - Diagnosed as chronic bronchitis } \\
\text { - Idiopathic } \\
\end{array}$ & $\begin{array}{rr}4 & \\
\cdot & 2 \\
\cdot & 2 \\
\end{array}$ & $13.3 \%$ \\
\hline
\end{tabular}


As regard the site of bleeding in group I:

MDCT can predict the site of bleeding in 24 (80\%) cases (all 22 cases of unilateral parenchymal findings in addition to 2 cases with bilateral bronchiectasis, yet with other features pointing to the site of bleeding as surrounding consolidation or dilated BA at the same side). MDCT cannot predict the site of bleeding in 6 cases, 2 cases with bilateral non-specific gravity dependent consolidations and 4 cases with no detected parenchymal abnormality.

Table (3): Shows the chest CT findings of the site of bleeding in the group I:

\begin{tabular}{|c|c|}
\hline Parenchymal abnormality & Number and percentage \\
\hline Unilateral parenchymal abnormality & $22(73.3 \%)$ \\
\hline - $\quad$ Mass & $13(43.5 \%)$ \\
\hline - $\quad$ Tuberculosis and its sequelae & $4(13.3 \%)$ \\
\hline - Focal Consolidation/ground-glass opacity & $2(6.7 \%)$ \\
\hline - $\quad$ Endobronchial mass & $2(6.7 \%)$ \\
\hline - Fungal (intra-cavitary mycetoma) & $1(3.3 \%)$ \\
\hline $\begin{array}{l}\text { Bilateral parenchymal abnormality } \\
\text { - Bronchiectasis } \\
\text { - } \quad \text { Consolidation/ ground-glass opacity }\end{array}$ & $\begin{array}{l}4(13.3 \%) \\
3(10 \%) \\
1(10 \%)\end{array}$ \\
\hline
\end{tabular}

VB was performed in three patients. Two patients had endobronchial masses in axial scans with distal airway obstruction and virtual bronchoscopy was done for better evaluation. In the first patient, the VB demonstrates the endobronchial mass and CT images showed the extra-luminal extension. In the second patient, there was endobronchial mass completely occluding the right lower lobe bronchus, with distal air way obstruction. The third patient had chronic non-resolving consolidation and virtual bronchoscopy was done to exclude endobronchial obstructing lesion. VB revealed patent airways in this patient.

Group II included 20 patients, underwent MDCT bronchial angiographic study. 10 patients underwent MDCT angiography using 16-raw MDCT. 10 patients had MDCT angiography study at 64-raw MDCT.

Table (4): Showed the classification of the patients presenting in group II:

\begin{tabular}{|l|l|l|}
\hline Cases & Number & percentage \\
\hline - Patient with prior routine CT chest study & 8 & $40 \%$ \\
- No parenchymal abnormality & 5 & $25 \%$ \\
- Consolidation & 2 & $10 \%$ \\
\hline$\quad$ Patients with no prior CT study & 1 & $5 \%$ \\
\hline
\end{tabular}

Table (5): Shows CT angiography findings as regard the cause of bleeding in group II:

\begin{tabular}{|c|c|}
\hline Parenchymal abnormality & $\begin{array}{l}\text { Number and } \\
\text { percentage }\end{array}$ \\
\hline Specific parenchymal abnormality & $11(55 \%)$ \\
\hline - $\quad$ Mass & $6(30 \%)$ \\
\hline - Bronchiectasis & $3(15 \%)$ \\
\hline - $\quad$ Tuberculosis and its sequelae & $2(10 \%)$ \\
\hline Non-specific parenchymal abnormality & $4(20 \%)$ \\
\hline $\begin{array}{c}\text { - Consolidation/ ground-glass opacity } \\
\bullet \quad \text { Diagnosed as pneumonia } \\
\cdot \quad \text { Non-specific }\end{array}$ & $\begin{array}{l}4(20 \%) \\
2 \\
2\end{array}$ \\
\hline No parenchymal abnormality & $5(25 \%)$ \\
\hline - Bronchial artery vascular abnormality (dilatation/ dysplasia) & $2(10 \%)$ \\
\hline - $\quad$ Pulmonary artery vascular abnormality (Pulmonary embolism) & $1(5 \%)$ \\
\hline - $\quad$ No vascular abnormality & $2(10 \%)$ \\
\hline
\end{tabular}


Table (6): Summarizes the CT findings and detection of the cause of hemoptysis in the two groups

\begin{tabular}{|l|l|l|}
\hline & Group I & Group II \\
\hline Parenchymal abnormality & $26(86.7 \%)$ & $15(75 \%)$ \\
\hline $\begin{array}{l}\text { Specific parenchymal } \\
\text { abnormality }\end{array}$ & $23(76.7 \%)$ & $11(55 \%)$ \\
\hline $\begin{array}{l}\text { Non-specific parenchymal } \\
\text { consolidation/ ground-glass } \\
\text { opacity }\end{array}$ & $3(10 \%)$ & $4(20 \%)$ \\
\hline Vascular abnormality & 0 & $3(15 \%)$ \\
\hline $\begin{array}{l}\text { Determination of the cause } \\
\text { applying all clinical and CT } \\
\text { findings }\end{array}$ & $27(90 \%)$ & $16(80 \%)$ \\
\hline $\begin{array}{l}\text { No cause identified (idiopathic } \\
\text { hemoptysis) }\end{array}$ & $3(10 \%)$ & $4(20 \%)$ \\
\hline
\end{tabular}

As regard the site of bleeding in group II:

Table (7): Shows the chest CT findings of the site of bleeding in the group II:

\begin{tabular}{|l|l|}
\hline Parenchymal abnormality & Number and percentage \\
\hline Unilateral parenchymal abnormality & $\mathbf{1 0}(\mathbf{5 0} \%)$ \\
\hline$\cdot \quad$ Mass & $6(30 \%)$ \\
\hline$\cdot \quad$ Tuberculosis and its sequelae & $2(10 \%)$ \\
\hline Focal Consolidation/ ground-glass opacity & $2(10 \%)$ \\
\hline Bilateral parenchymal abnormality $\quad$ Bronchiectasis & $\mathbf{5 ( 2 5 \% )}$ \\
• Consolidation/ ground-glass opacity & $3(10 \%)$ \\
\hline Vascular abnormality & $2(10 \%)$ \\
\hline No abnormality detected & $\mathbf{3 ( 1 5 \% )}$ \\
\hline
\end{tabular}

In the total 50 patients of both groups in our study, the MDCT chest revealed unilateral findings in 32 (64 $\%)$ of cases and bilateral findings in $9(18 \%)$ cases. The site of bleeding was identified in $39(78 \%)$ patients.

Table (8): Summarizes the CT findings and detection of the site of hemoptysis in the two groups

\begin{tabular}{|l|l|l|}
\hline & Group I & Group II \\
\hline $\begin{array}{l}\text { Unilateral parenchymal } \\
\text { abnormality }\end{array}$ & $22(73.3 \%)$ & $10(50 \%)$ \\
\hline $\begin{array}{l}\text { Bilateral parenchymal } \\
\text { abnormality }\end{array}$ & $4(13.3 \%)$ & $5(25 \%)$ \\
\hline Site of bleeding & $24(80 \%)$ & $15(75 \%)$ \\
\hline
\end{tabular}

The source of bleeding: CT angiography revealed the source of bleeding in 15 patients (75\%). In our study, CT angiography study could reveal all the arteries causing hemoptysis. The arteries causing hemoptysis were dilated and traceable to the level of pulmonary hila.

Table (9): showed the source of bleeding detected in group II:

\begin{tabular}{|l|l|l|}
\hline Source of bleeding detected & $\begin{array}{l}\text { With parenchymal } \\
\text { abnormality }(\mathbf{6 0} \%)\end{array}$ & $\begin{array}{l}\text { Without parenchymal } \\
\text { abnormality (15\%) }\end{array}$ \\
\hline $\begin{array}{l}\text { Bronchial artery supply } \\
\mathbf{( 5 0 \% )}\end{array}$ & $8(40 \%)$ & $2(10 \%)$ \\
\hline $\begin{array}{l}\text { Non-bronchial systemic } \\
\text { artery (15\%) }\end{array}$ & $3(15 \%)$ & 0 \\
\hline Pulmonary artery (10\%) & $1(5 \%)$ & $1(5 \%)$ \\
\hline Not detected (25\%) & $3(15 \%)$ & $2(10 \%)$ \\
\hline
\end{tabular}

Number of bronchial arteries: As regard the number of BAs detected at CT angiography study, 50 bronchial arteries were detected in 20 patients. 20 right BAs seen in 18 patients (two patients had two 
right BAs and at two patients the right BA could not be detected), 30 left BA seen in the 20 patient (10 patients with single left BA and 10 patients with double left BA).

$40(80 \%)$ of BAs were orthotopic (17 right and 23 left). 10 (20\%) ectopic BAs were seen in 7 patients, 3 at the right side ( 2 from aortic arch and 1 from subclavian artery (SCA) and 7 at the left (5 from aortic arch, 2 from lower aorta). The origins of orthotopic mediastinal bronchial arteries were best depicted on overlapping axial thin-section images (e.g. 1-mm-thick sections at $0.75-\mathrm{mm}$ increments). Twodimensional MIP reformatted images in the coronal oblique and sagittal planes readily depict the tortuous trajectories of the bronchial arteries from their origins (descending thoracic aorta) to the lungs along the main bronchi; reformatted images in straight coronal planes are better suited for analysis of the intercostal and internal mammary arteries; and axial reconstructed images are ideal for demonstrating the inferior phrenic arteries and branches from the celiac axis. Dilated $(>2 \mathrm{~mm})$ and/or tortuous bronchial arteries were identified in 20 arteries (40\%) in 10 patients, 15 of the 20 were orthotopic and 5 were ectopic. Dilated intercostal vessels with pleural thickening $(>3 \mathrm{~mm})$ and parenchymal lung abnormalities were found in 2 patients $(10 \%)$. One enlarged NBSAs seen arising from the celiac trunk.

Table (10): shows the origin and diameter of the BAs detected by CT study

\begin{tabular}{|l|l|l|l|l|}
\hline \multirow{2}{*}{ Detected bronchial arteries } & \multicolumn{2}{l|}{ Right (20) } & \multicolumn{2}{l|}{ Left (30) } \\
\cline { 2 - 5 } & Dilated & Non-dilated & Dilated & Non- dilated \\
\hline Orthotopic (40) & 10 & 7 & 5 & 18 \\
\hline Ectopic (10) & 2 & 1 & 3 & 4 \\
\hline
\end{tabular}

Table (11): Shows the origin of the bronchial arteries in relation to the aorta and tracheal carina:

\begin{tabular}{|c|c|c|}
\hline $\begin{array}{l}\text { Origin of orthotopic bronchial } \\
\text { artery }\end{array}$ & Right (17) & Left (23) \\
\hline In relation to aorta & $\begin{array}{ll}\cdot & 6 \text { medial } \\
\cdot & 6 \text { antero-medial } \\
- & 5 \text { postero-medial }\end{array}$ & $\begin{array}{ll}\text { - } & 13 \text { anterior } \\
\text { - } & 4 \text { antero-medial } \\
\text { - } & 6 \text { antero-lateral }\end{array}$ \\
\hline In relation to tracheal carina & $\begin{array}{ll}\text { - } & 9 \text { at carina } \\
\text { - } & 8 \text { below carina }\end{array}$ & $\begin{array}{ll}- & 7 \text { at carina } \\
\text { - } & 16 \text { below carina }\end{array}$ \\
\hline
\end{tabular}

43 of 50 (86\%) BAs were traceable to the hilum (27 left and 16 rights), 7 BAs were non-traceable (3 left and 4 rights). 2 patients (10\%) had pulmonary vascular origin as a source of bleeding, including pulmonary artery dilatation in the inner wall of a cavitary lesion in 1 patient $(5 \%)$, and thromboembolism in 1 patient $(5 \%)$.

\section{DISCUSSION}

Hemoptysis is defined as bleeding arising from the lower airways. It is a common and nonspecific sign, occurring in a wide variety of diseases. (9) Its presence always requires investigation, even if only a small quantity of blood is expectorated ${ }^{(10)}$. Identifying the etiology of hemoptysis and classifying it in terms of the amount of blood expectorated play a fundamental role in defining the treatment and deciding whether or not hospital admission is necessary. In addition, the rate of bleeding is the major determinant of mortality, and asphyxia is the leading cause of death. ${ }^{(11)}$ The etiology of hemoptysis can be divided into several groups: infections; cardiovascular diseases; lung diseases; cancer; vasculitis; coagulopathy; 
trauma; drug use; iatrogenesis; foreign body aspiration; and cryptogenic hemoptysis. (9) Cryptogenic hemoptysis, for which no cause can be identified, is a diagnosis of exclusion and might be expected to decrease in prevalence with more systematic use of CT. ${ }^{(1,2)}$ Massive hemoptysis usually originates from the BAs, due to the high pressure of that circuit. ${ }^{(12,13)}$ The normal BA is a small vessel that arises directly from the descending thoracic aorta and supplies blood to the airway of the lung, esophagus, and lymph nodes. $(12,14,15)$ Bronchial arteries show substantial anatomic variations in their origins, branching patterns, and courses. ${ }^{(15)}$ The right intercostobronchial trunk, which usually arises from the right posterolateral aspect of the thoracic aorta at the level of the $5^{\text {th }}$ thoracic vertebra or $6^{\text {th }}$ thoracic vertebra, is the most constant vessel. In approximately $70 \%$ of cases, there are two left BAs. Right and left BAs that arise from the aorta as a common trunk are not unusual. BAs are identified in the posterior mediastinum as dots or lines of increased attenuation. ${ }^{\left({ }^{(9)}\right.}$ More than $30 \%$ of BAs have an anomalous origin, which is a cause of endovascular treatment failure. ${ }^{(8)}$ Anomalous BAs may originate from the aortic arch, internal mammary artery, thyrocervical trunk, subclavian artery, costocervical trunk, brachiocephalic artery, peri-cardiophrenic artery, inferior phrenic artery, or abdominal aorta. ${ }^{(8)}$ The imaging modalities pertinent to the evaluation of hemoptysis include chest radiograph, CT, MDCT and bronchial arteriography. (16)
Radiography can help lateralize the bleeding and can often help detect underlying parenchymal and pleural abnormalities. (16) Revel et al, (7) found that chest radiography defines the site of bleeding in only $46 \%$ of patients. This nearly coincides with results of our study, where chest radiography contributes to the diagnosis of hemoptysis in only 22 of 50 patients (44\%) including patients with lung cancer (12 patients), bronchiectasis (4 patients), tuberculosis (2 patients) and consolidation (4 patients). Published studies (e.g. Hirschberg et al ${ }^{(17)}$ \& Revel et al ${ }^{(7)}$ on the efficacy of single detector row spiral CT have already demonstrated the capacity of this imaging technique to help predict the site of bleeding as accurately as bronchoscopy and to help detect underlying disease with high sensitivity. Thus, the purpose of our study was to evaluate the role of MDCT in patients presenting with hemoptysis to reach a diagnosis and in the depiction and traceability of bronchial and NBSAs as well as pulmonary arteries. In the present study, group I included 30 patients underwent chest MDCT including MPR, MIP and 3D reformatted images. Group II included 20 patients underwent CT bronchial angiography study. According to results of the present study in the total 50 patients, the MDCT study revealed the cause of bleeding in 43 (86 $\%$ ) cases. Most common cause of bleeding was lung mass (19 cases with peripheral or central lung masses and 2 endobronchial masses), transthoracic or bronchoscopic biopsy was done in 20 cases and revealed bronchogenic carcinoma in 


\section{ROLE OF MULTISLICE COMPUTED TOMOGRAPHY....}

19 (38 \%) cases. Other causes were bronchiectasis in $6(12 \%)$ patients, tuberculosis and its sequelae in $6(12 \%)$ patients. No cause could be identified in 7 (14\%) of cases. According to the results of Khalil et al., (8), MDCT scans showed the cause of bleeding in 48 of 53 patients $(90.5 \%)$. This nearly agreed with the result in our study, where MDCT identified the cause of hemoptysis in 43 of 50 patients $(86 \%)$. Although exact percentages vary in large general populations, in most reports (e.g. Millar et al., (18), Hirshberg et al., (17), bronchiectasis, chronic bronchitis, tuberculosis, fungal infection and malignancy are the most common important causes of hemoptysis. In general this nearly coincides with the results of our study with the exception of chronic bronchitis, as most of those patients diagnosed clinically. Also Khalil et al., (19) reported five major causes of hemoptysis: bronchiectasis, active tuberculosis, lung cancer, sequelae of tuberculosis, and cryptogenic causes. These five causes represented $80 \%$ of all cases of hemoptysis in this study. Other studies showed different results. In another recent study done by Soares Pires et al., (4), the researchers revealed that pulmonary tuberculosis sequelae and bronchiectasis were the dominant diagnoses (22.2\% and $15.8 \%$, respectively), followed by lung cancer. The etiology of hemoptysis was not established in $6.3 \%$. Regarding the bleeding site localization in the present study, the presence of bleeding was detected by abnormal CT findings in the form of focal parenchymal abnormality or opacity (either ground glass opacity or consolidation) that is not gravity-dependent. Diffuse opacities or predominantly in the dependent portion of the lungs were considered non-localizing. Several studies Revel et al., (16) \& Khalil et al., (8) described three types of nonspecific radiologic MDCT abnormalities: (1) ground-glass opacities and/or (2) alveolar consolidation; the latter abnormalities were considered to reflect the filling of the alveolar lumen with blood, and (3) atelectasis, induced by clots obstructing the bronchi. Presence of alveolar filling, cavitation and/or a mass were considered to be localizing lesions. Haponik et al., (20) in a retrospective study of 32 patients with hemoptysis showed that CT correctly localized site of bleeding in 23 of the 26 patients $(88 \%)$ in whom a site was identified by FOB. In our study, in group I, MDCT revealed the site of bleeding in 39 of 50 (78\%) patients. In group II, we detected 50 bronchial arteries. Similar results obtained by Yoon et al., (21) who detected 52 bronchial arteries in 22 patients, using 16 MDCT. Mortia et al., ${ }^{(22)}$ detected 223 bronchial arteries in 73 patients, using 16-detetor or 64detector MDCT using 3D (volume rendering) post-processing techniques. As regard the ostia of bronchial arteries, our study showed that 40 of $50(80 \%)$ of the BAs seen are orthotopic, 17 of $20(85 \%)$ on the right side, and 23 of 30 (76.6 $\%)$ on the left side. 10 bronchial arteries were found to be ectopic. This coincides with Remy Jardin et al., (23) study, who found the ostia of the right and left BAs to be orthotopic in $83 \%$ of cases on the right side and in $73 \%$ of cases on 
the left side. They also found that CT angiography was very helpful in depicting bronchial arteries of ectopic origin. They found four (17\%) of 23 right arteries and eight (27\%) of 30 left arteries adequately depicted on CT angiograms having an ectopic origin. In our study, the detected 10 ectopic bronchial arteries were seen in 7 patients (35\% of patients). This nearly coincides with Hartmann et al., ${ }^{(24)}$ study, which evaluated 214 patients with hemoptysis on 4-, 16-, and 64-detector row MDCT scanners and detected the presence of ectopic bronchial vessels in $36 \%$ of patients. Morita et al., (22) studied the BA anatomy using 16 or 64 - detector row MDCT. An orthotopic origin was observed in $93 \%$ of the right ICBT, $73 \%$ of the direct origin right $\mathrm{BA}, 79 \%$ of the common trunk of both BAs, and $79 \%$ of the left bronchial arteries. Mori et al., (25) found that among 41 patients underwent 16-slice-MDCT study, a total of 102 bronchial artery ostia were detected. 80 bronchial arteries were orthotopic (78.4\%) and a total of 22 ectopic BAs were depicted (21.6\%). 13 patient (42\%) had at least $1 \mathrm{BA}$ of ectopic origin. Dilatation and tortuosity of BAs were found in 8 patients (40\%). Yoon et al., ${ }^{(21)}$ found that differences in diameters between bronchial arteries causing hemoptysis and those not causing hemoptysis were not statistically significant. However, they found that differences in the percentage of traceability to the hilum of bronchial arteries causing hemoptysis and those not causing hemoptysis were statistically significant. Therefore, they concluded that $16-$ detector row CT provides information as to which bronchial artery (artery of traceability) should be selected in the interventional procedure. Helmy et al., (26) also found that tortuosity and traceability of the vessels directed towards the lesion are more important factors in identification of the source and site of bleeding. We found that 43 of $50(86 \%)$ BAs were traceable to the hilum (27 left and 16 rights), 7 BAs were non-traceable (3 left and 4 rights) and these cases were considered suboptimal. Yoon et al., ${ }^{(21)}$ found $34(65 \%)$ of 52 BAs were traceable from their origins to the hilum. We believe that this difference is due to that they use 16detector row MDCT. We believe that the use of 64-detector row MDCT increases the ability to detect and trace the BAs. They also reported that BAs responsible for bleeding can frequently be visualized and traced from their origin to the level of the pulmonary hilum (74\%), where $11 \%$ of BAs not responsible for bleeding can be traced that far. Conventional bronchial angiography was performed after CT study in only 4 patients indicated for embolization. Dilated bronchial arteries were identified in 3 patients and dilated nonbronchial systemic arteries were seen in 2 patients. In our study, CT angiography study could reveal all the arteries causing hemoptysis. The DSA findings regarding systemic arterial source of bleeding in 12 patients (17\%) indicated for embolization were as follows: In 10 of 12 patients, 10 bronchial arteries (8 right and 2 left) were evaluated with selective angiography. All of 


\section{ROLE OF MULTISLICE COMPUTED TOMOGRAPHY....}

these bronchial arteries arose from the descending thoracic aorta, 2 of 8 right bronchial arteries arose from intercostobronchial trunk whereas 6 right and 2 left bronchial arteries arose directly from the descending thoracic aorta. Five nonbronchial arteries were evaluated (3) right intercostal and 2 left intercostals arteries). Also we found that right BAs were easily visible, traceable and depicted than left BAs, we think this is due to the long course of right $\mathrm{BA}$ from origin at the left paramedian line at the level of left main bronchus through the mediastinum toward the right hilum. As regard the location of the bronchial artery ostium on circumferential wall of thoracic aorta, we found that on the right side (total 17 arteries): 6 $(35.3 \%)$ arise from medial wall, $6(35.3 \%)$ arise from antero-medial aspect 5 arise from the postero-medial aspect. On the left side (total 23 arteries): 13 arise from the anterior aspect, 4/23 arises from the antero-medial aspect and 6/23 arises from the antero-lateral aspect. Morita et al., (22) detected 114 bronchial arteries on the right side, $80(70.2 \%)$ right bronchial arteries arose from the medial-to-anteromedial wall of the thoracic aorta, whereas $29.8 \%$ arose from the lateral-to-anterior wall. On the left side, they detected 105 left bronchial arteries, of 63 directorigin left bronchial arteries, $46(73 \%)$ arose from the anterior-to-lateral wall of the thoracic aorta, whereas 17 (27\%) arose from the medialto-anteromedial wall. According to the study done by Yoon et al., (27), a pleural thickness of more than $3 \mathrm{~mm}$ and the presence of systemic vessels within an extra-pleural fat layer considered CT criteria for the presence of a NBSA supply. In our study, combined findings including enlarged non-BAs, pleural thickening and parenchymal abnormalities were considered as non-bronchial source of bleeding. Nonbronchial source of bleeding was encountered in three patients, two intercostal arteries and one from celiac trunk. Khalil et al., ${ }^{(28)}$ found that of total 272 patients presenting with hemoptysis, 13 patients $(6.9 \%)$ had hemoptysis of pulmonary artery origin. This agreed with result of other previous reports Sbano et al., ${ }^{(29)}$. In our study, the pulmonary circulation was found to be the source of hemoptysis in $10 \%$ of cases. In the present study, MDCT with 3D-VB reconstruction was performed in 3 patients. Two patients had endobronchial masses in axial scans with distal airway obstruction and virtual bronchoscopy was done for better evaluation. In the first patient, the VB nicely demonstrates the endobronchial mass and CT images showed the extra-luminal extension and distal 2ry parenchymal consolidations. In the second patient, there was endobronchial mass occluding the right lower lobe bronchus. CT shows the distal consolidation. Fiberoptic bronchoscopy was done in those two patients and confirmed the CT findings. Biopsy was taken from both lesions and revealed bronchogenic carcinomas. The third patient had chronic non-resolving consolidation and cannot undergo FOB. Virtual bronchoscopy was done to exclude endobronchial obstructing lesion. VB revealed 
patent airways in this patient. Fiberoptic bronchoscopy was not done in this patient. Fiberoptic bronchoscopy was done in 7 patients with moderate or severe hemoptysis. It revealed the cause of bleeding in 6 patients $(85.7 \%), 3$ patients had central bronchogenic carcinoma (proved by histopathological confirmation), 2 patients had focal endobronchial mass and 1 patient had bronchiectasis. Biopsy was taken from the 5 patients with central or endobronchial masses.

\section{Limitations:}

There were some limitations of our study, such as the small number of patients enrolled especially in group II. Another limitation is that the selective angiography and bronchoscopy was performed in a limited number of patients. To confirm our observations, a larger study is needed in which inter-observer variability, especially in defining BAs causing hemoptysis and those not causing hemoptysis, is recommended with use of CT and angiography.

\section{CONCLUSION}

Applying the findings of the current study, it is concluded that MDCT is considered a primary noninvasive imaging modality in the evaluation of patients with hemoptysis. It also serves as a guide for other diagnostic or therapeutic procedures.

Case (1):
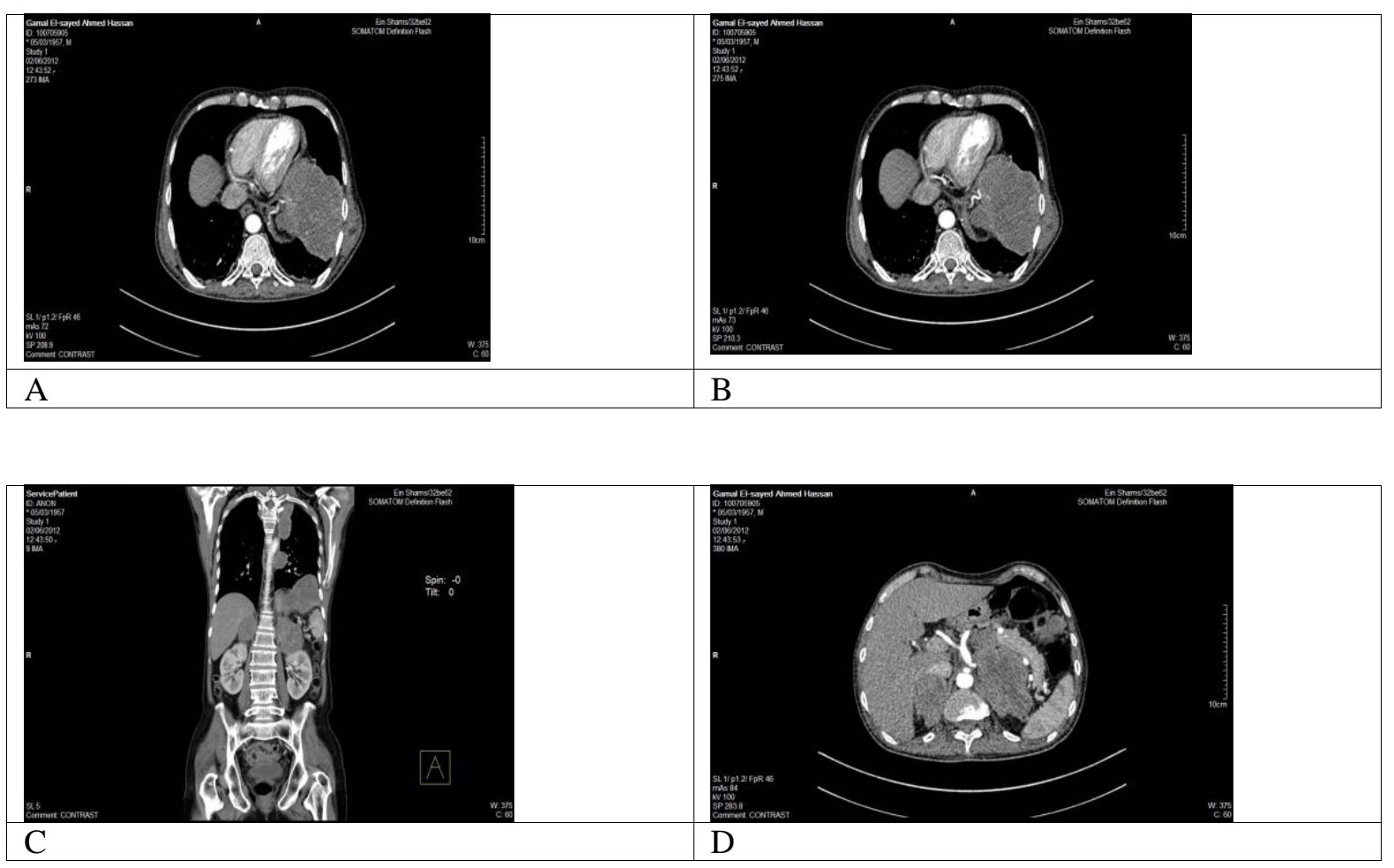

Fig. (1): Axial CT images (A \& B): revealed large left lower lobe mass, with no definite clear fat plane between the mass and the left lateral aspect of the pericardium. Abnormal dilated vessel is seen coursing towards the large mass. Caudal axial images (C) and coronal reformatted images (D) revealed bilateral large supra-renal masses.

Case (2): 


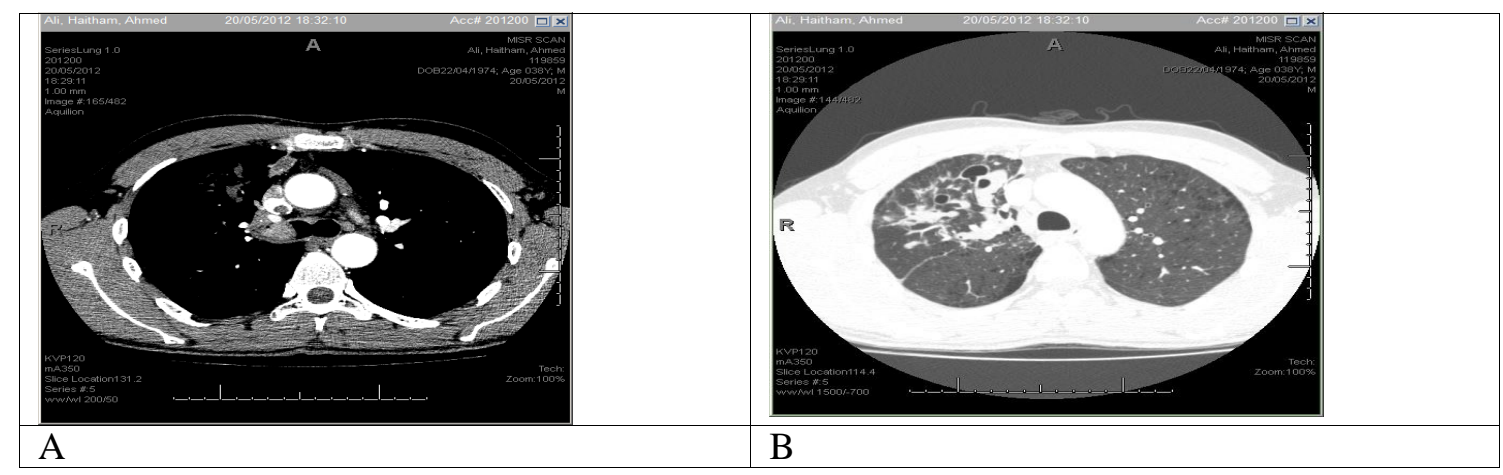

Fig. (2): axial CT cuts, mediastinal window (A) and lung window (B) show mass infiltrating the right mainstem bronchus (white arrow). Distal bronchiectatic changes and consolidations are also seen.
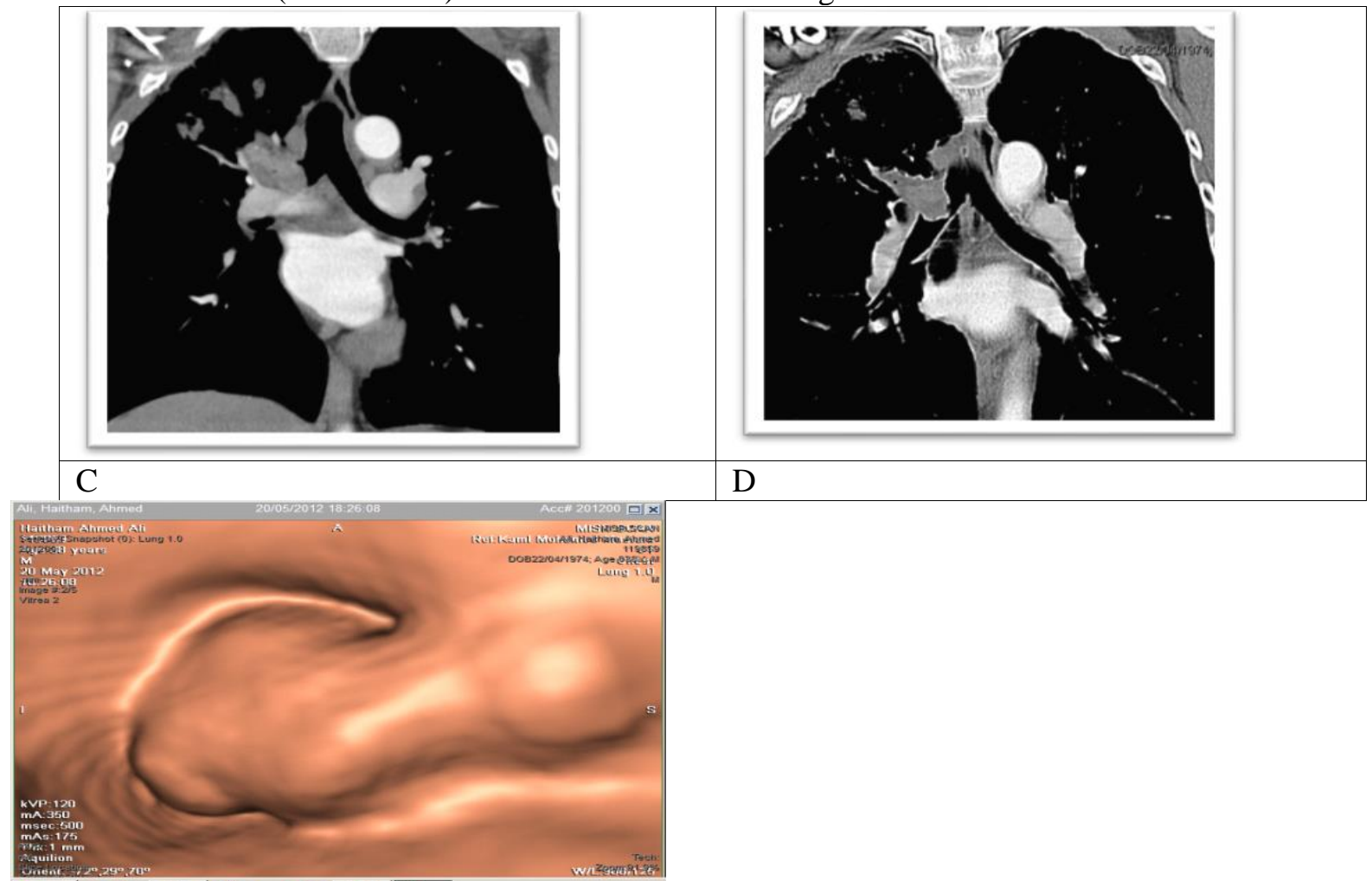

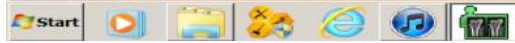

(E)

Fig. (3): (C \& D) Coronal reformatted CT images the mass infiltrating the right mainstem bronchus. (E) CT virtual bronchoscopy image showing the right mainstem bronchus mass.

Case (3):

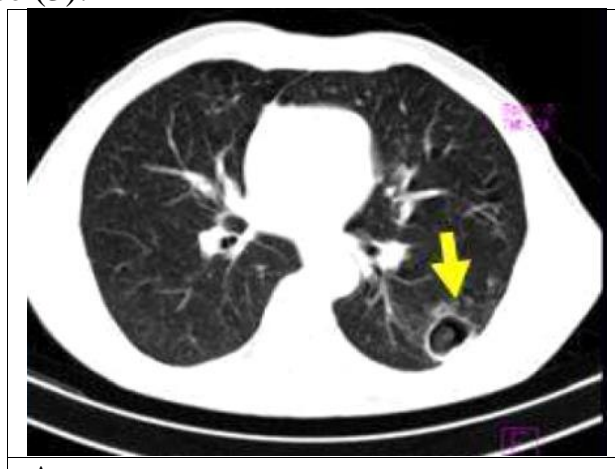

A

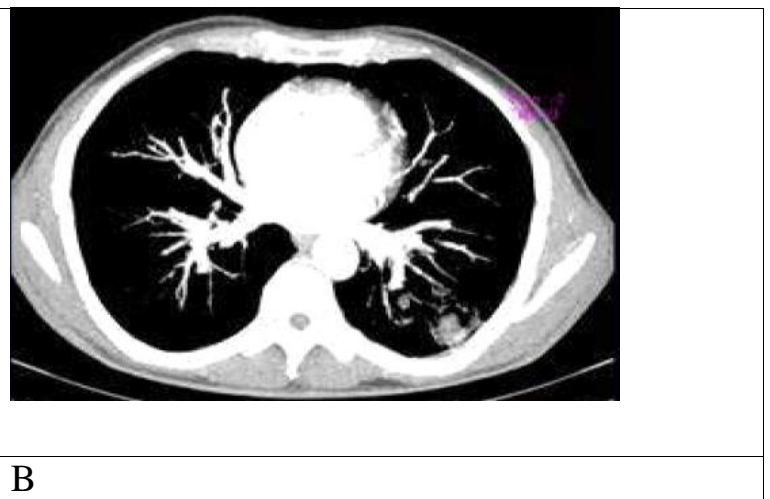



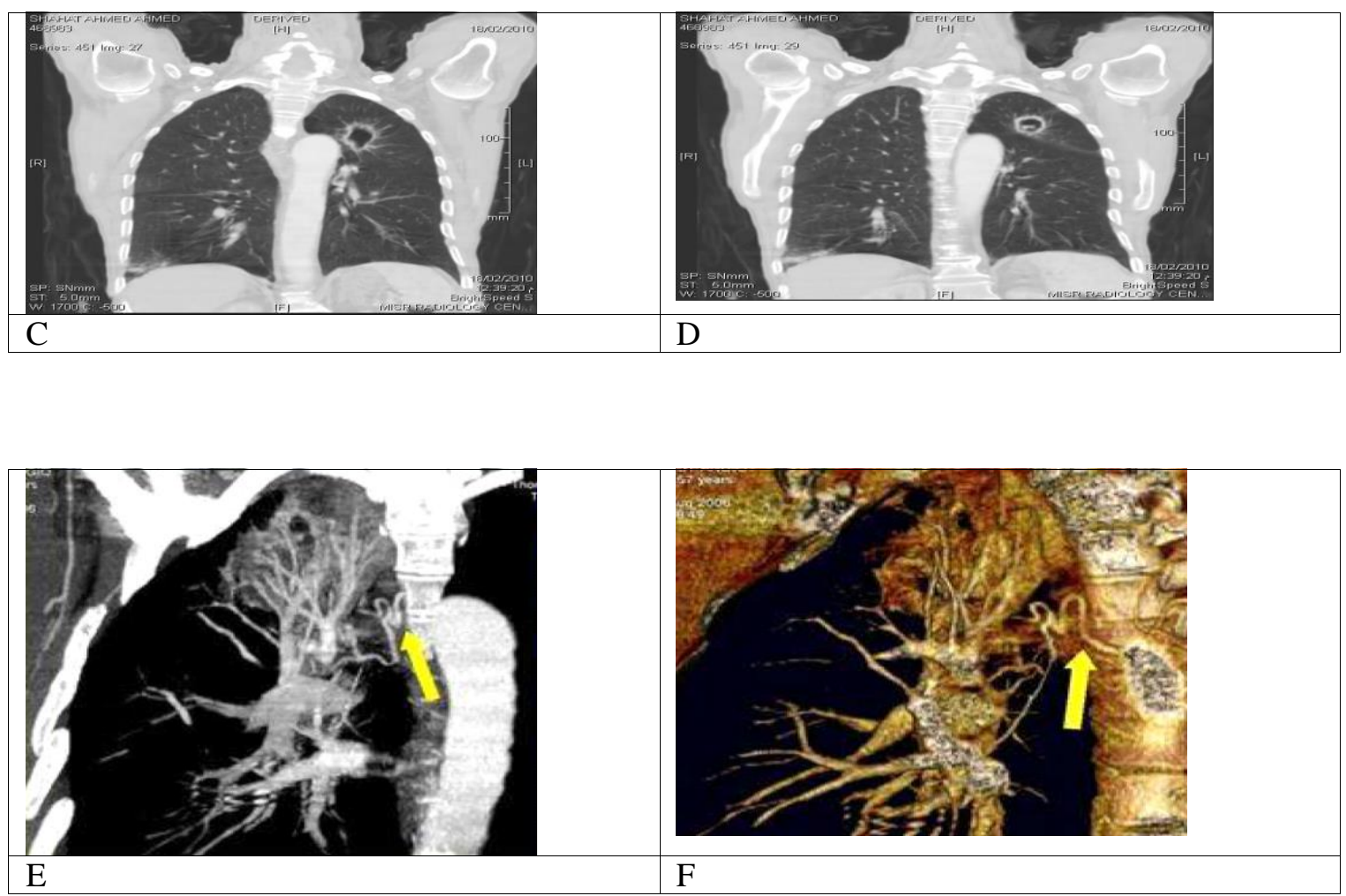

Fig. (3): Axial (A \& B) and coronal reformatted images (C \& D) showing thin-walled cavitary lesion seen at the left upper lobe, with intra-cavitary solid nodule (arrows). E: sagittal oblique reformatted CT Angiography images. F: 3D VR CT Angiography images. E \& F revealed dilated tortuous left bronchial artery seen directed towards the lesion.

Case (4):
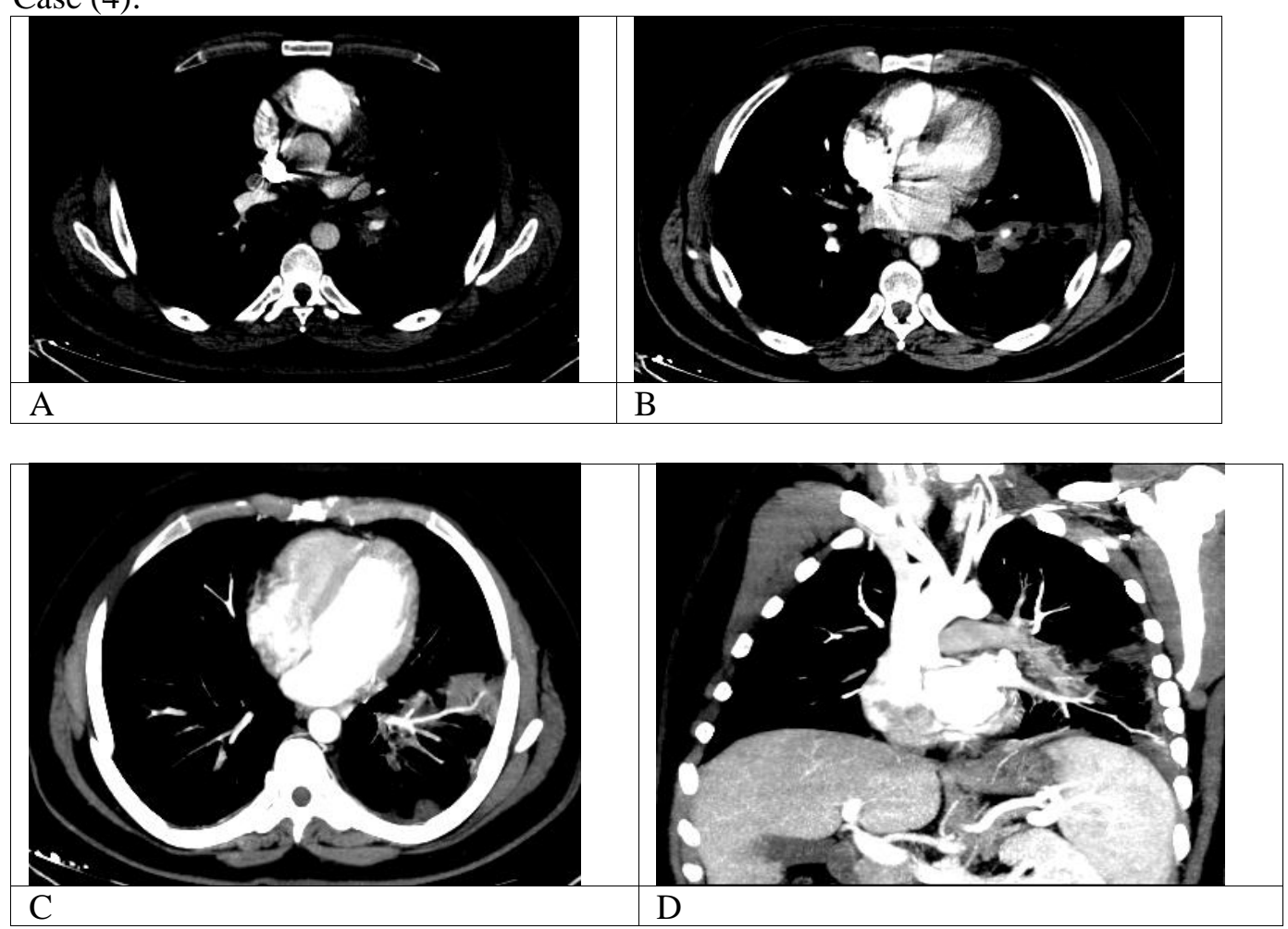


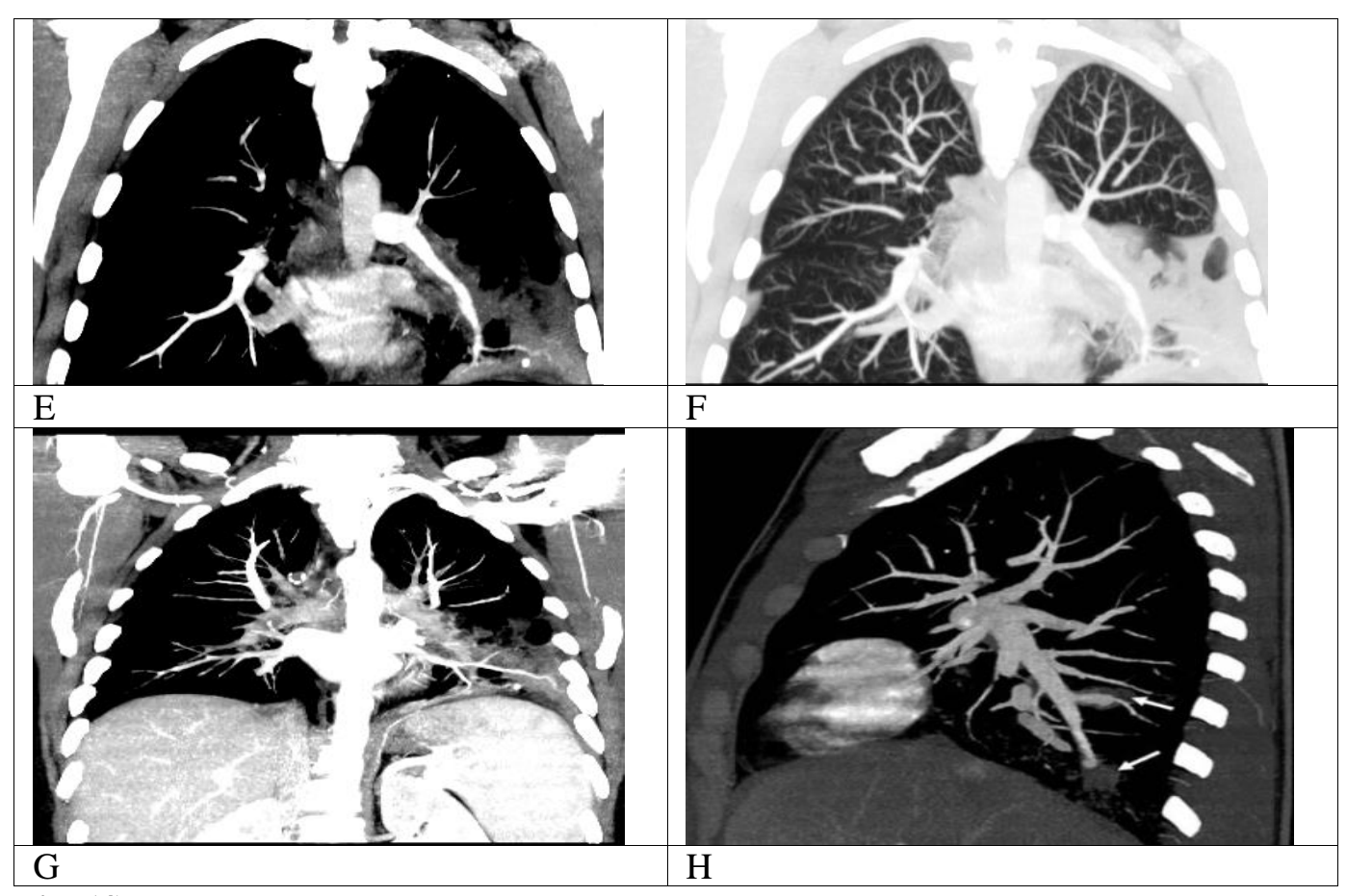

Fig. (4): Axial images (A, B, C), Coronal Maximum intensity projection (MIP) (D,E,F, G) and sagittal (H) CT images showing left lower lobe consolidation and cavitation (white star at E \& G). The left descending pulmonary artery is seen dilated and bordering the inner wall of the consolidation and cavity (white arrow at $\mathrm{E}$ and black arrow at F).

Case (5):
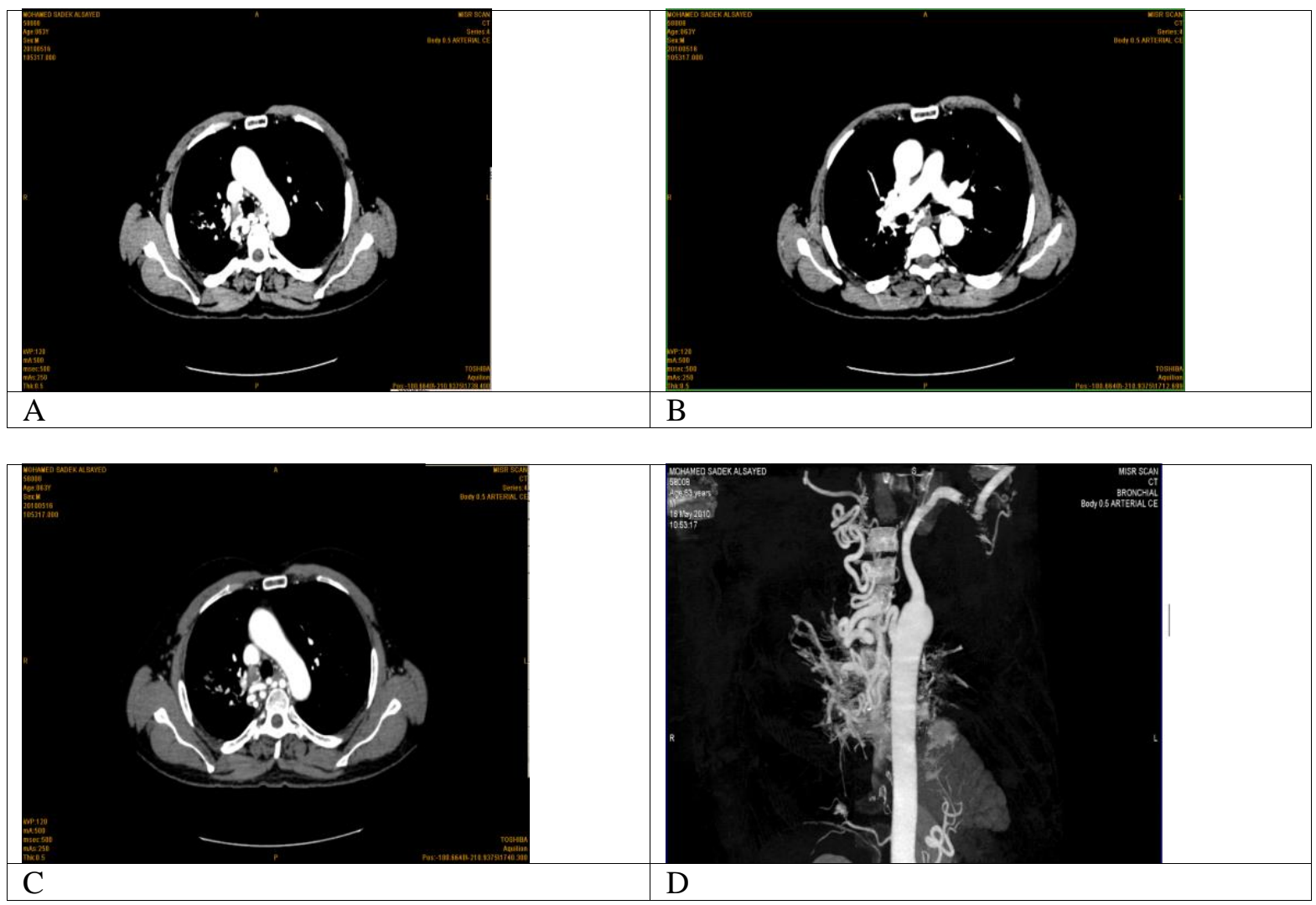

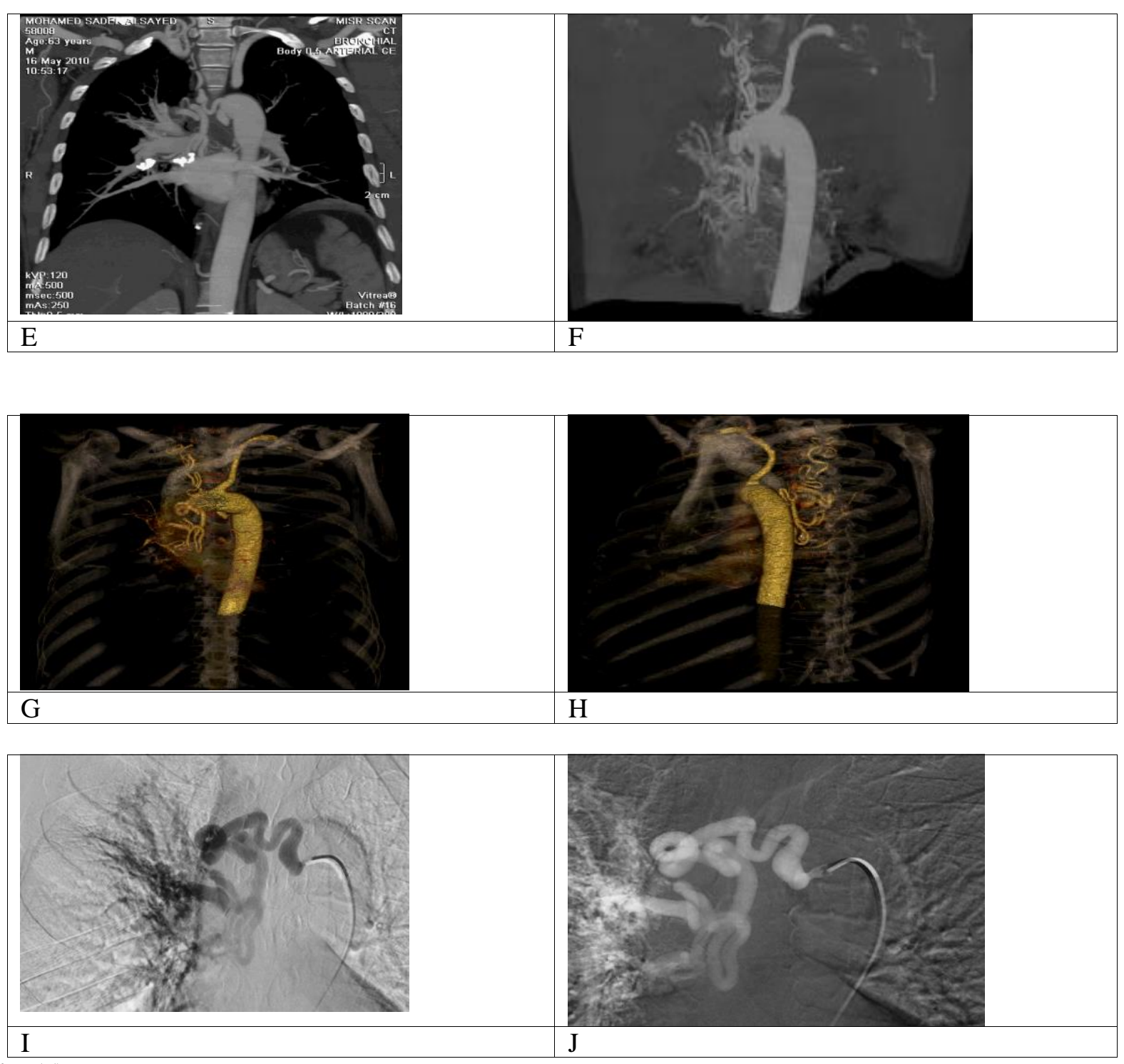

Fig. (6): Axial images (A, B and C) CT images showing multiple enhancing dots at the mediastinum represent the markedly dilated and tortuous right bronchial artery (black arrows) arising directly from the aorta. Coronal MIP images (D, E, and F) showed the abnormally dilated right bronchial artery (white arrows). 3D VR images (G: anterior view and H: posterior view) more clearly demonstrates the dilated and tortuous right bronchial artery (white arrows), its origin from the aorta as well as its mediastinal course. (I, J) Digital subtraction angiography images (DSA) confirmed the CT findings

\section{References:}

- Bruzzi JF, Remy-Jardin M, Delhaye D, et al., (2006): Multi-detector row CT of hemoptysis.

- Jeudy J, Khan A R, Mohammed T, et al.,(2010): Expert Panel on Thoracic Imaging: American College of Radiology ;

- Andersen P. (2006): Imaging and interventional radiological treatment of hemoptysis. Acta Radiologica; (47): 780 - 792

- Soares Pires F, Teixeira N, Coelho F, et al., (2011): Hemoptysis - etiology, evaluation and treatment in a university Hospital. Pneumol.; 17(1):7-14.

- Sirajuddin \& Mohammed (2008): 44-year-old man with hemoptysis: A review of pertinent imaging studies and radiographic interventions. Cleveland clinic journal of medicine; (75): 601607.

- Chun, Young J, Morgan R, et al., (2010): Radiological Management of Hemoptysis: A Comprehensive Review of Diagnostic Imaging 


\section{ROLE OF MULTISLICE COMPUTED TOMOGRAPHY....}

and Bronchial Arterial Embolization. Cardiovasc Intervent Radiol; (33):240-250

- Revel M, Fournier L, Hennebicque A, et al. (2002): Can CT replace bronchoscopy in the detection of the site and cause of bleeding in patients with large or massive hemoptysis?. AJR; (179):1217-1224.

- $\quad$ Khalil A, Fartoukh M, Tassart M, et al., (2007): Role of MDCT in Identification of the Bleeding Site and the Vessels Causing Hemoptysis. AJR; 188:W117-W125.

- Lundgren C, Costa A M, Figueiredo L C, et al., (2010): Hemoptysis in a referral hospital for pulmonology. 36(3):320-324.

- Marsico GA, Montessi J. (2002): Hemoptise. In: Tarantino AB, editor. Doenças pulmonares. Rio de Janeiro: Guanabara Koogan; 22-31.

- Johnson J, (2002): Manifestations of hemoptysis. How to manage minor, moderate, and massive bleeding. Postgrad Med.; 112(4):101-6, 108-9, 113.

- $\quad$ Lordan JL, Gascoigne A, Corris PA. (2003): The pulmonary physician in critical care Illustrative case 7: Assessment and management of massive haemoptysis. Thorax; 58(9):814-9.

- Fernandez A. (2006): Hemoptise. In: Lopes AC, Neto VA. Tratado de clínica médica. São Paulo: Roca;. p. 4678-80.

- Barker AF. (2002): Bronchiectasis. N Engl J Med.; 346(18):1383-93.

- Catalano C, Napoli A, Fraiolo F, et al., (2005): Multidetector-Row Computed tomography: scanning and contrast protocols. Chapter; Abdominal aorta, renal arteries and run off vessels. Springer, 1st edition, 79.

- Shitrit D, Valdsislav P, Grubstein A, et al. (2005) Accuracy of Virtual Bronchoscopy for Grading Tracheobronchial Stenosis* Correlation With Pulmonary Function Test and Fiberoptic Bronchoscopy. Chest; 128: 3545-50.

- Hirshberg B, Biran I, Glazer M, et al., (1997): Hemoptysis: etiology, evaluation, and outcome in a terciary referral hospital. Chest; (112):440-4.

- Millar A, Boothroyd E, Edwards D, Hetzel R. (1992): The role of computed tomography (CT) in the investigation of unexplained haemoptysis. Respir Med; 86(1):39-44.
- Khalil J, Fartoukh M, Parrot A, et al., (2010): Impact of MDCT Angiography on the Management of Patients With Hemoptysis. AJR; 195:772-778

- Haponik EF, Britt EJ, Smith PL, Bleecker ER. (1987): Computed chest tomography in the evaluation of hemoptysis. Impact on diagnosis and treatment. Chest; 91(1):80-85.

- Yoon Y, Lee K, Jeong Y, et al., (2005): Hemoptysis bronchial and nonbronchial systemic arteries at 16-detector row CT. Radiology; (234): 292-298.

- Morita Y, Takase M, Ichikawa H, et al., (2010): Bronchial Artery Anatomy: Preoperative 3D Simulation with Multidetector CT. Radiology; (255): 3

- Remy-Jardin M, Bouaziz N, Dumont P, et al., (2004): Bronchial and nonbronchial systemic arteries at multi-detector row CT angiography: comparison with conventional angiography. Radiology; (233):741-749

- Hartmann I C, Remy-Jardin M, Menchini L, et al., (2007): Ectopic origin of bronchial arteries: assessment with multidetector helical CT angiography. Eur Radiol; (17):1943-1953.

- Mori H, Ohno Y, Tsuge Y, et al., (2010): Use of Multidetector Row CT to Evaluate the Need for Bronchial Arterial Embolization in Hemoptysis Patients. Respiration;(80):24-31

- Helmy S A, Hafez S A, Hegab S E et al., (2009): Role of Multidetector Row Computed Tomography in Evaluation Of Hemoptysis. Bull. Alex. Fac. Med.; (45).

- Yoon W, Kim Y, Kim J, et al., (2003): Massive hemoptysis: prediction of nonbronchial systemic arterial supply with chest CT. Radiology; (227):232-238

- Khalil A, Parrot A, Nedelcu C, et al., (2008): Severe hemoptysis of pulmonary arterial origin: signs and role of multidetector row CT angiography. Chest; (133) :212-219

- Sbano H, Mitchell A, Ind P, et al., (2005): Peripheral pulmonary artery pseudo aneurysms and massive hemoptysis. AJR; 184(4):12531259. 


\section{دور التصوير المقطعي بالكمبيوتر في علاج المرضى الذين يعانون من نزيف الام

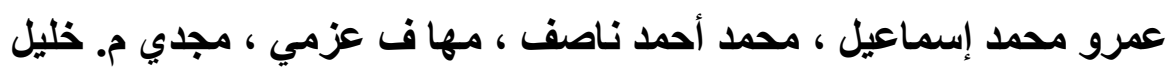

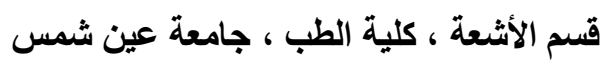

قمنا بوصف دور التصوير المقطعي بالكمبيوتر، مع التطبيقات الجديدة لتحديد سبب النزيف وموقعه، وتحديد فائدة إضافية

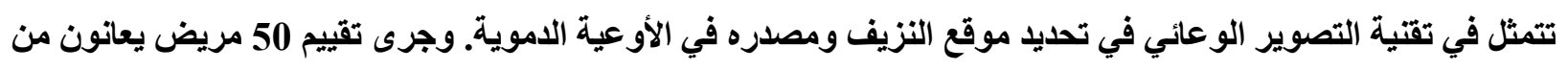
نزيف الام مع التطبيقات الجديدة وتقنية طرق التصوير الوعائي على المرضى.

النتائجج: كثف التصوير المقطعي بالكمبيوتر أنه طريقة ممتازة لتثخيص نزيف الام.

يعتبر التصوير المقطعي بالكمبيوتر هي الطريقة الأساسية للتصوير الموسع في تقييم المرضى الذين يعانون من نزيف الدام. كما أنه بمثابة دليل للإجراءات الأخرى التثخيصية أو العلاجية. 